\title{
REPORT OF THE WORKING GROUP ON THE UNIVERSAL PERIODIC REVIEW. MEXICO. ADDENDUM. VIEWS \\ ON CONCLUSIONS AND/OR RECOMMENDATIONS, VOLUNTARY COMMITMENTS AND REPLIES PRESENTED BY THE STATE UNDER REVIEW
}

\section{COMPLEMENTARY RESPONSE OF THE GOVERNMENT OF MEXICO TO THE RECOMMENDATIONS IN THE REPORT OF THE WORKING GROUP ON THE UNIVERSAL PERIODIC REVIEW (A/HRC/11/27)*}

1. The Mexican government's response is organized by topic. In addition to general comments, information is also provided on some of the important progress that has been made in Mexico over the last few months in the area of human rights. This information complements the information provided by the Mexican government in its National Report $(\mathrm{A} / \mathrm{HRC} /$ WG.6/4/MEX/1).

\section{A. REGULATORY AND INSTITUTIONAL FRAMEWORK}

\section{Constitutional and Legislative Harmonization and the Incorporation of International Standards}

\section{(Recommendations in paragraph 93- Numbers 1 to 7)}

2. On April 23, 2009, the Chamber of Deputies of the Mexican Congress passed a draft decree containing several amendments to the Constitution on human rights. The draft is currently being studied by the Senate, which will analyze it upon the start of their deliberations next September. Among other topics, the decree proposes to include full Constitutional recognition of the human rights acquired through international treaties that Mexico has ratified; the pro persona principle in the application of human rights norms; and the obligation of the authorities

* During the session of the Working Group on the Universal Periodic Review, the Mexican government accepted the recommendations contained in paragraph 93 of the report of the Working Group (A/HRC/11/27). 
to promote, respect, protect and guarantee human rights and the State's obligation to prevent, investigate and sanction human rights violations. It includes, as a principle of foreign policy, respect for and the protection and promotion of human rights. It also includes express recognition of the right of all persons to request asylum. Regarding national and state-level human rights institutions, the decree states that the heads of these institutions and their advisory boards will be elected through a process of public consultations and social participation and that the authorities that do not accept the recommendations arising from this process must publish their reasons for doing so. It also includes the obligation to guarantee the technical and budgetary autonomy of the state institutions.

\section{Implementation of the National Human Rights Programme}

(Recommendation of paragraph 93- No. 9)

3. Mexico has strengthened the publicity of the 2008-2012 National Human Rights Programme (NHRP) by means of a campaign in the printed media to make the programme known to the general public. Regarding the implementation and monitoring of the NHRP, all of the authorities involved will give the Ministry of the Interior (SEGOB for its initials in Spanish) periodic reports on the degree to which the programme has been implemented. The subcommittee that was created in December 2008 within the Government's Human Rights Policy Commission to evaluate and follow up on the NHRP is in charge of monitoring the programme, and includes the participation of civil society.

\section{B. Civil AND Political Rights}

\section{Administration of Justice and Public Security}

(Recommendations in paragraph 93- Numbers 24, 25, 29, $34,35,37,38,40$ to 42,44 to $47,50,51$ )

4. Mexico continues its efforts to promote the implementation of the 2008 Constitutional amendments to the public security and criminal justice system, to fight impunity and to modernize the justice system.

5. On January 2, 2009, the General Law on the National Public Security System was issued to regulate its composition, organization and op- 
eration. It includes the requirements for a career in the police force and as public prosecutor; for the professionalization of and training for federal, state and municipal public security institutions; certification processes and loyalty assessments to evaluate and certify the entrance and continuance of the public security and ministerial personnel. It also includes principles, responsibilities and limits to the rational use of force by the personnel of the public security institutions.

6. As a consequence of the above-mentioned law, on March 2, 2009 it was agreed to create a National Network of Public Security Institutions to facilitate cooperation and coordination with law enforcement and justice administration authorities. In addition, human rights training programs for police forces and other public servants were strengthened as part of the ongoing efforts with the National Human Rights Commission, the International Committee of the Red Cross and academic institutions. From January 1, 2009 to March 31, 2009, 2,919 public servants received training, which makes a total of 52,551 individuals who have received training since December 2006.

7. On May 30, 2009, the new Organic Law of the Attorney General's Office entered into force. It includes new processes to certify and ensure the professionalism of the agents of the Federal Public Prosecutor's Office through evaluation systems and human resource development that guarantee their suitability and the integrity of their actions. In addition, on June 2, 2009, the new Law of the Federal Police, presented by the President's office, entered into force. This law recognizes the investigative capabilities of the police and facilitates their cooperation with the Federal Public Prosecutor's Office in order to align the State's capabilities for fighting organized crime. In addition, it seeks to strengthen the certification process and professionalization of the police forces as well as the procedures for disciplining and applying sanctions to police personnel, all within the framework provided by the guiding principles of legality, objectivity, efficiency, professionalism, honor and full respect for human rights in the performance of the federal police.

8. In regard to the judicial system, on October 13, 2008, the Technical Secretariat of the Coordinating Council for the Implementation of the Criminal Justice System was created. This is a decentralized administrative body of the Ministry of the Interior that assists with training programs on the criminal justice system for judges, agents of the Federal Public Prosecutor's Office, police, defenders, experts, lawyers and the gen- 
eral public. It also carries out programs to explain the system and, in general, works with the relevant entities on policies, programs, mechanisms and draft legislative reforms to assure that the criminal justice system functions on all three levels of government. In addition, the Mexican government extended an invitation to the Special Rapporteur on the Independence of Judges and Lawyers to make an official visit to Mexico in the first half of 2010 in order to learn about the reforms made to the criminal justice system and to discuss them with the actors involved with them.

9. The rights of detainees were strengthened by the 2008 Public Security and Criminal Justice System reform. As follow-up, on January 23, 2009, several articles of the Federal Code of Criminal Procedure were modified to reflect the obligation of the authorities to report any detentions or arrests without delay, and to bring the detainee before the corresponding prosecutorial official immediately; the official must guarantee that the detainee's fundamental rights have not been violated. In addition, Congress is analyzing a new draft of the Federal Law of the Execution of Criminal Sanctions in order to provide legal authorities with ways to control and monitor the execution of sentences and security measures, while observing at all times the rights of the detainees and those serving sentences in federal social rehabilitation centers.

10 . With the opening of new penitentiaries and the closing of inoperative installations, the global overcrowding of the Mexican prison system was reduced from September 2008 to March 2009 from 32.5\% to $30.16 \%$, that is, while the prison population grew by 1,345 inmates during this period, the number of beds increased by 4,013. In accordance with the General Law of the National Public Security System, on March 30, 2009 the National Conference of the Penitentiary System was inaugurated to coordinate the work of making the country's prison system uniform. In addition, in May 2009, the National Academy of Penitentiary Administration was created to train prison personnel, both the security forces and the custodial staff, as well as technicians at the federal and local level.

11. On June 1st, 2009, a decree was issued through which the protection of personal data, rectification and cancellation of it, is given constitutional ranking. Through the recognition of the constitutional action of habeas data, the population has access to procedural means for the protection of their privacy and security, thus fulfilling one of the objectives 
of the National Human Rights Programme: "Promote the necessary initiatives in the legislation about personal data and archive protection".

\section{I.1 The Military Justice System}

(Recommendations in paragraph 93- Numbers 36 and 43; Recommendations in paragraph 94-Numbers 3, 4, 5, 6 and 7).

12. The 2008-2012 National Human Rights Programme includes "promoting reforms to the military justice system in accordance with the international human rights commitments adopted by the Mexican State". The dialogue regarding this objective will take place within the Government's Human Rights Policy Commission, where Mexican civil society organizations participate actively.

13. The recommendation included in paragraph 94.4 has been resolved since the June 2008 Public Security and Criminal Justice System reform, which establishes a rights-based accusatory criminal trial system that gives the aggrieved party and the accused more participation in the legal process in accordance with the highest international standards. Implementation of this amendment implies adapting, among other legal bodies, the Code of Military Justice in order to harmonize it with the above-mentioned Constitutional amendment and with the international human rights instruments ratified by Mexico. This harmonization process is currently underway, with the objective, among others, to give even more transparency to the military tribunal procedures and broaden the participation of the victims therein, as established in the Constitution according to the aforementioned reform.

14. Mexico continues its prompt investigation of all allegations of human rights violations committed by members of the armed forces. In this context, and in conformity with the Mexican Constitution, military jurisdiction investigates and sanctions these acts when they are committed while on active duty or as a consequence of such, that is, those acts committed by elements of the military while on a mission, while obeying an order they have received or while performing their operational or administrative functions. When military personnel conduct themselves in a way considered to be a violation of human rights, the army prosecutor begins the corresponding investigation; the process is carried out in military tribunals through public hearings and the Code of Military Justice is applied, or where appropriate, the federal or non-federal criminal codes 
based on the universal principles that govern the legal due process, principles that apply equally to all individuals within the framework of Mexican legislation.

15. Recommendation 94.3 and the first part of recommendation 94.6 have been overcome due to the fact that de jure and de facto, in Mexico, the civil legal system prevails over the military judicial process, because the sentences of the military courts and the Supreme Military Court can be appealed before the civil courts by means of an action for amparo. In this way, the competent federal civil courts ultimately determine the legality of the decisions of the military courts that are based on the Code of Military Justice and, as necessary, the constitutionality of the code itself. Between 2001 and 2008, there were 558 indirect applications for amparo in district courts and 400 direct applications for amparo in the collegiate circuit courts against the decisions of the military courts and the Supreme Military Court. The amparo was granted in 152 and 209 cases, respectively.

16. As mentioned before, the military jurisdiction has the authority to investigate, process and sanction military personnel who commit crimes in the exercise of their duty, that could be considered violations of human rights. Furthermore, during the current administration, the Defense Ministry has accepted all of the recommendations made by the National Human Rights Commission and coordinates closely with the commission in order to comply with the recommendations. When the recommendations demonstrate human rights violations by military personnel, the Ministry intervenes with the internal control body, of the Ministry of Public Administration, and/or the army prosecutor's office. In such cases, reparations have been provided to victims according to the Regulation of constitutional article 113 (Federal Act on Responsibility for Financial Injury). The Military Justice system currently investigates 6 cases that are in the preliminary investigation phase, 3 cases in which 32 military personnel have been brought before the authorities, and there are 9 registered convictions against 14 military personnel. In addition, the Working Group on Arbitrary Detention, the Subcommittee for the Prevention of Torture and the National Mechanism for the Prevention of Torture, have carried out visits to military facilities where, in all cases, the required cooperation has been given. Thus, the Mexican State considers that military jurisdiction is being carried out efficiently in order to prevent, prosecute and sanction violations of human rights that may be committed by military personnel in the exercise of their duty, reason for 
which it is not possible to the recommendation support the recommendation contained in paragraph 94.5.

17. Regarding the recommendation contained in the second part of paragraph 94.6, the armed forces are involved in public security tasks on a temporary basis as established in the 2008-2012 National Human Rights Programme. They participate in a complementary fashion, assisting civil authorities when expressly asked to do so, as stated by jurisprudence of the Supreme Court. The protection of human rights by military personnel is reinforced through intensive training in human rights and through the thorough investigation and punishment, if necessary, of conduct by elements of the military that is considered to violate human rights. The Defense Ministry recently agreed on a joint program of cooperation with the Office of the United Nations High Commissioner for Human Rights in Mexico that is in addition to the cooperation already in place with the International Committee of the Red Cross, as well as a cooperation agreement with the National Institute for Women, which will soon be signed. Additionally, a dialogue mechanism with civil society organizations in all of the national territory regarding human rights and gender perspective has been implemented and is being strengthened. A program of equality between men and women is also being worked on for the Army and the Air Force.

18. The Mexican State does not support recommendation 94.7 because military jurisdiction over offenses committed by members of the Armed Forces in the exercise of their duty is established in the Constitution itself and its objective is to preserve military discipline. Because of the specificity of the matter, it is legally unsustainable to have a parallel and alternate jurisdiction over crimes committed by military personnel in the exercise of their duty. The Constitution also allows for the appeal of sentences handed down by military tribunals and by the Supreme Military Court before the competent federal civil courts by means of an action for amparo [Source: Sedena/SRE-DGDH].

\section{I.2 Arraigo}

(Recommendations in paragraph 93- No. 39; Recommendation in paragraph 94- No.2)

19. With the June 2008 Public Security and Criminal Justice System reform, the criminal justice system throughout the country was funda- 
mentally transformed. As regards to arraigo, the Constitutional reform limits its sphere of application specifically to crimes committed by the organized crime (which fall under federal jurisdiction), and it is subject to strict legal controls: it can only be determined by a federal judicial authority specialized in the area at the request of the Federal Public Prosecutor's Office when it is strictly necessary for the success of the investigation. by giving the Federal Public Prosecutor's Office the opportunity to integrate a duly supported accusation, due to the fact that regarding organized crime, the evidence for the accusation is complex and difficult to obtain, including due to the transnational nature of the crime; it is for such reason that the individuals must remain under custody. In addition, because of the relevance of the affected interests and the dangerous nature of those involved, the objective of arraigo is also to protect individuals or legal assets, or when there is the risk that the accused might flee from justice. To this effect, the Constitutional reform created the figure of a "control judge," as the independent and specialized federal judicial authority in charge of immediately handling requests for arraigo. Among the responsibilities of the control judges is to ascertain that the rights of the indicted, the victims and/or the injured parties are not violated during the proceeding and to verify the legality of the actions of all involved. The defendant can at any time during arraigo, present him or herself before the judicial authority to question the legality of the conditions under which he/she is being held and the duration of it. Arraigo is, therefore, an exceptional measure whose application is strict and limited and is taken when it is impossible for the Federal Public Prosecutor's Office to investigate an act of organized crime in 96 hours when it is an in flagrante delicto arrest, and it is used in order to have the elements to guarantee the success of the investigation. According to the Constitution, the arraigo cannot exceed forty days, which can be extended if the Federal Public Prosecutor's Office proves that the causes that led to the arraigo still exist, in which case the total duration of the arraigo cannot exceed eighty days.

20. In light of the recent reforms, arraigo is an extraordinary precautionary measure that complies with the standards established in the International Covenant on Civil and Political Rights and within the Body of Principles for the Protection of All Persons under Any Form of Detention or Imprisonment. Arraigo is determined by a specialized judicial authority (control judge) under conditions and procedures determined by 
law. This judicial authority is designated based on the principles of transparency and impartiality that are needed to guarantee the effective operation of the judicial system.

21. In addition, individuals subject to arraigo enjoy the rights of due process on a basis equal to any individual subject to any other form of detention. When arraigo is applied, all intimidation or torture is prohibited; the individual must be informed of his/her alleged crime and rights and cannot be held incommunicado; and the individual must be guaranteed full access to a lawyer and the right to an adequate defense among other guarantees established by Constitutional article 20 which reflects articles 9, 10 and 14 of the International Covenant on Civil and Political Rights. The remedy of amparo proceeds against the decision of the control judge and guarantees protection of these rights. In addition, individuals under arraigo receive medical care and attention.

22. Furthermore, the Mexican State has a mechanism that enables it to constantly monitor and, if necessary, modify this figure to cover any gaps that might appear. The 2008-2012 National Human Rights Program includes, among its lines of action, "promoting the use of the figure of arraigo under the strictest legal criteria".

23. Similar figures to arraigo are found in other legislative systems. As in the Mexican case, legislation in some other countries allows detention for prolonged periods of time before establishing charges in the event of some grave crimes, while the investigation is taking place, subject to judicial control.* For all the above mentioned reasons, Mexico does not support recommendation 94.2.

\section{I.3 Definition of Organized Crime}

\section{(Recommendation of paragraph 94- No.1)}

24. The Mexican legislation is in accordance with the United Nations Convention against Transnational Organized Crime (Palermo Convention), ratified by Mexico on March 4, 2003.The Palermo Convention es

* Domiciliary arraigo is known in Italy as "house arrest"; both figures operate in the same way. These figures are subject to judicial control in some countries (for example: Colombia, the United States, France, Italy) and not in other countries (United Kingdom for terrorism cases). The duration of house arrest varies in different States, reaching even up to six months (United States). 
tablishes a judicial framework for international cooperation in the prevention and fight against organized crime; it establishes the minimum commitments from which the Parties can adopt measures in accordance with their national legislation. Thus, in conformity with article 34.3 of the Palermo Convention, the Mexican State has adopted measures that are stricter than those of the Convention to prevent and combat organized crime, with full respect for human rights. The Palermo Convention does not contain a definition of "organized crime," and only defines in article 2 the term "organized criminal group" but solely for the purposes of the Convention itself.

25. The Mexican government fulfills its obligation to "criminalize participation in an organized criminal group," contained in article 5 of the Convention through: (i) the figure of "organized crime," established in the Constitution and in the Federal Law against Organized Crime, and (ii) the figure of "criminal association" established in the Federal Criminal Code.

26. With the June 2008 Constitutional amendment to the Public Security and Criminal Justice System, organized crime was defined in Constitutional article 16 paragraph eight as "a de facto organization of three or more persons that commits crimes in a permanent or repeated way as defined by the law on the subject". The purpose of this definition is to limit the application of the measures included in the Constitution to combat organized crime in order to apply criminal law only to groups with criminal objectives and to no others. Furthermore, the Federal Law against Organized Crime establishes the crime of organized crime according to the Constitutional definition and provides an exhaustive list of the crimes that it sanctions: terrorism; crimes against health; counterfeiting or altering currency; operations with illicitlyacquired funds; stockpiling and trafficking in arms; trafficking in undocumented persons; trafficking in organs; the corruption of minors, pornography involving minors, sexual tourism involving minors, enslavement of minors, the assault or kidnapping of or trafficking in minors; stealing vehicles; trafficking in persons; and crimes that are included in the Federal Criminal Code, the Federal Law on Firearms and Explosives, the General Population Act, the General Law on Health and the Act to Prevent and Punish Human Trafficking. In addition, "participation in an organized criminal group" is penalized through the crime of criminal association which is classified in article 164 of the Federal Criminal Code. 


\section{I.4 Special Prosecutor's Office for Past Political and Social Movements}

\section{(Recommendation of paragraph 94- No.8)}

27. The Special Prosecutor's office to address probable federal crimes committed directly or indirectly by public servants against individuals linked to past social and political movements (Femospp for its title in Spanish), was created in November 2001 as an administrative unit of the Attorney General's Office. In November 2006, the Attorney General's Office, through resolution A/317/2006, remitted to the General Coordinating Office for Investigations (CGI for its initials in Spanish) of the Deputy Attorney General's Office for the Specialized Investigation of Federal Crimes (within the Attorney General's Office) all of Femospp's pending cases. The CGI has the same (and other) attributions as the Femospp in terms of the investigation and prosecution of crimes. Therefore, no investigations were interrupted and the victims' rights were preserved. The CGI has continued the ongoing investigations and the criminal processes, making efforts to clarify the facts and to get statements from the aggrieved parties, witnesses and character witnesses for those under indictment. Recently, important efforts have been made including the inspection and scanning with advanced technology of areas where clandestine burials have been verified as well of the excavation of these places in search of human remains. 28. By a presidential resolution dated November 27, 2001, all of the federal ministries, the governments of the federal entities and all private citizens were invited to transfer to the $\mathrm{Na}$ tional Archives all important information related to past events. In compliance with this resolution, the National Archives have provided access to 6,846 documents and cards from these files in 2002; to 13,709 in 2003; to 7,031 in 2004; to 11,183 in 2005; to 7,635 in 2006; to 3,523 in 2007 and to 7,822 in 2008. In addition, since 2001 there has been an Interdisciplinary Committee for the Reparation of Damages to Victims or Aggrieved Parties for Human Rights Violations to Individuals Linked to Past Social and Political Movements in relation to the cases of alleged enforced disappearances in the 1970s and 1980s, identified in 2001 by the National Human Rights Commission. 


\section{Freedom of Expression}

(Recommendations in paragraph 93- Numbers 52 to 61)

29. Congress is studying an initiative to amend the Constitution that was presented on October 30, 2008 by the executive branch in order to consider as federal crimes those related to (among others) violations to the freedom of expression, which, because of their social importance and way in which they operate, transcend state limits or those of the Federal District. In addition, on April 2, 2009, the Chamber of Deputies passed an initiative with reforms to the Federal Criminal Code that are currently being studied by the Senate. These reforms would allow crimes that impede, interfere with or attack journalists' activities to be investigated by federal authorities. Specifically, the National Human Rights Programme includes as one of its objectives "promoting the necessary legislative reforms to permit effective action by the corresponding federal authorities in cases of crimes committed against journalists while exercising their profession".

\section{Combating Torture}

(Recommendations in paragraph 93- Numbers 26 to 28)

30. The new January 2009 General Law on the National Public Security System includes among the obligations of security institution personnel that of "abstaining at all times from inflicting or tolerating acts of torture, even when ordered by superiors or when special circumstances are argued, such as a threat to public security, urgent investigations or any other; any awareness of torture must be brought to the immediate attention of the competent authorities".

\section{COUNTERING DisCRIMINATION AND RIGHTS OF SPECIFIC GROUPS}

\section{Women}

(Recommendations in paragraph 93- Numbers 8, and 11 to 23)

31. To date, the General Act on Equality between Women and Men, in force since 2006, has been replicated in 10 federal entities. 32. In fol- 
low-up to General Act on Women's Access to a Life Free From Violence, in force since 2007, currently 32 federal entities have local legislation on this topic. In addition, seven have passed the rules and regulations for the law and 21 have created a state mechanism to coordinate with local police on this issue. Domestic violence is recognized as a cause of divorce in the 32 federal entities and is classified as a crime in 29 of them. Rape between spouses is classified as a crime in 18 federal entities, and sexual harassment is classified as a crime in 26 federal entities.

33. On April 16, 2009, the official Mexican standard NOM-190SSA1-1999 was modified, becoming "NOM- 046-SSA2-2005. Domestic and sexual violence and violence against women. Criteria to prevent and address it". This standard sets forth the role of health institutions, government agencies and organizations in providing medical attention to individuals involved in domestic or sexual violence, as well as the criteria for detecting and preventing it and for providing medical attention and guidance in such cases from a gender perspective in order to understand in a comprehensive fashion the problem of violence. It also sets forth the obligation of the institutions to provide the victim with medical abortion services at her request (or at the request of her legal representative if the victim is a minor) in the event of a pregnancy resulting from rape with the prior authorization of the competent authority and after providing complete information about the possible risks and consequences. 34. For 2009 , the budget earmarked for the national policy on equality between women and men and to fight violence against women is approximately nine billion pesos. These resources will be used to (i) support the 32 state mechanisms for advancing women's causes; (ii) create entities for women in various municipalities (to date approximately 800 have been created); (iii) support the projects of civil society organizations that address violence against women through the Proequality Fund (which since 2002 has financed more than 350 projects); (iv) operate the Vida sin Violencia (Life without Violence) hotline that has provided free and confidential psychological and legal advice (in 2008 it took approximately 22,000 calls from women in violent situations); and (v) create campaigns to raise awareness about the issue.

35. In the first quarter of 2009, the Special Prosecutor's office for crimes of violence against women and trafficking in persons (Fevimtra for its initials in Spanish) of the Attorney General's Office began 25 pre- 
liminary investigations of crimes of violence against women, handled 341 new cases and followed up on 734 incidents in the Comprehensive Care Centers, providing legal and emotional support among other services. It also has a program of prevention for this area.

36. Strengthening the investigations of the homicides of women in Ciudad Juárez, Chihuahua has yielded results. According to information from the Chihuahua State Attorney General's Office, from January 1993 to December 2008, 447 cases were opened of which as of March 2009: 201 were fully resolved by jurisdictional organs by issuing final decisions and sanctioning those responsible; 51 are ongoing, including the arrest of the individuals allegedly responsible; 17 were sent to juvenile court given that the accused were minors; four were sent to Fevimtra because they were federal cases; 20 cases were closed as they were suicides; and 155 are under preliminary investigation. [Source: SREDGDH]

37. On June 1, 2009, a decree was issued by which the competencies of the Commission for the Prevention and Eradication of Violence against Women in Ciudad Juárez were expanded converting it into an institution with authority in all of the national territory. In this way, the National Commission for the Prevention and Eradication of Violence against Women was created as a decentralized agency of the Ministry of the Interior. The commission is in charge of preventing, addressing, sanctioning and eradicating violence against women throughout the country, and elaborating among others the Integral Program to Address, Sanction and Eradicate Violence against Women.

\section{Indigenous Peoples}

(Recommendations in paragraph 93- Numbers 8, 11, 48, 49, 64, 67 to $70,73,75$ to 78 )

38. The Constitution recognizes, among other rights of indigenous peoples, that "in all trials and proceedings in which they take part, individually or collectively, their customs and cultural specificities will be taken into account," and that "the indigenous peoples have the right at all times to the assistance of interpreters and to legal defense with knowledge of their language and culture".

39. In order to respect the methods by which the indigenous peoples and communities traditionally resolve conflicts, the Superior Court of 
Justice has created specialized courts that use their normative systems and their own languages and where the judges are elected by a community assembly.

40. The National Institute of Indigenous Languages (Inali for its name in Spanish) promotes the training of translators and interpreters certified in linguistics and legal issues to assist and advise translators in various entities such as district and criminal courts in the various states, civil courts, public prosecutors' offices and the Agrarian Court. The Federal Institute of Public Defenders has 25 bilingual federal public defenders since March 2009 who are expert in 20 indigenous languages.

41. The 2009-2012 National Program for the Development of the Indigenous Peoples (to be published in the near future) sets the objectives, indicators, goals, strategies and actions through which the federal government promotes development with identity, that is, with respect and recognition of the cultures and languages of the indigenous peoples and communities in Mexico in full adherence to the National Development Plan and within the framework of the Living Better strategy (Vivir Mejor). One of the program's central goals is to redouble its efforts to promote the economic development of the indigenous peoples and the construction of housing, to improve the delivery of potable water, electricity and sewers, among other services, to build and modernize rural roads and feeders, in addition to improving access to the new telecommunication technologies.

\section{Children}

(Recommendations in paragraph 93- Numbers 11, 30, 31 and 33)

42. The National System for the Integral Development of the Family (SNDIF in Spanish), through its Program for the Protection and Integral Development of Children, promotes: (i) the topics of Prevention of and Attention to Urban Child Labor and Prevention of and Attention to Street Children and Youth "From the Street to Life"; (ii) implementation of national and local action plans in the federal entities to prevent, address and eradicate the sexual exploitation of minors. For this, actions are currently being taken in 241 cities in 21 federal entities; and (iii) actions derived from the preventive strategy entitled Strengthening the Family as a Protective Space and the Promotion of Good Treatment. 
43. The National Human Rights Programme includes among its objectives "Creating programs to provide systematic and continual training in human rights, including children's rights, to all individuals who work with and for children". To date, there are 30 follow-up and monitoring committees for the application of the Convention on the Rights of the Child at the state level.

\section{Migrants}

(Recommendations in paragraph 93- Numbers 79 to 81)

44. After reforms to the General Population Act in July 2008 that decriminalized undocumented migration, Mexico has continued its efforts to guarantee migrants' human rights. Protection is provided, among other means, through the Beta Groups for the Protection of Migrants, the offices of the fifth visitaduria of the National Human Rights Commission, and the model for the protection of the rights of unaccompanied migrant and repatriated children and youth, under which 180 officials were trained in the protection of children in 2008. In addition, the Cross-Border Worker Migration Form guarantees the documentation of foreign temporary workers and their families. Thus strengthening their human and labor rights and enabling them to work, make purchases and open bank accounts. The migratory regularization program that has been in effect since November 2008 for foreign citizens of any nationality in Mexico without the proper documents has led to 57 regularizations of migratory status through February 2009. On April 1, 2009, the "Women Migrants" portal was launched as a pilot program for women and families linked to the migratory phenomenon to provide them with information and public services from civil society organizations, the three levels of government, academia and the private sector on human rights, health, jobs, and digital literacy.

\section{Human Trafficking}

(Recommendation in paragraph 93- No. 32)

45. On February 28, 2009, the Regulation of the Act to Prevent and Punish Human Trafficking went into effect. These regulations regulate the functions and competence of the Intersecretarial Committee to Prevent and Sanction Trafficking in Persons, which will coordinate govern- 
mental actions to draft and implement the National Program to Prevent and Sanction Trafficking in Persons that will be part of a comprehensive State policy, as well as the related sectorial and special programs. It also establishes the obligations of the relevant authorities related to the protection of, attention to and assistance for the victims, and details the criminal and migratory procedures to follow regarding the crime of human trafficking. 46. The Special Prosecutor's Office on Violent Crime against Women and Human Trafficking of the Attorney General's Office (Fevimtra for its title in Spanish) carries out its functions based on the Model of Action with a Focus on the Victim.

\section{ECONOMIC, SOCIAL AND CULTURAL RightS}

\section{Combating Poverty}

\section{(Recommendations in paragraph 93- Numbers 10, 65, 66 and 67)}

47. The NHRP includes in its objectives "Assure that the programs and policies to eradicate poverty address the dimensions of the poverty and discrimination faced by women in rural areas and by the indigenous peoples and communities". In April 2009, the federal government signed a World Bank loan for USD\$1, 503,750,000 to strengthen the "Opportunities" Human Development Program to improve the health and education of the target families, of which 1.3 million belong to indigenous households in 17,700 localities in all of the indigenous municipalities in Mexico. This will be achieved by conditional cash transfers, promoting medical checkups to improve health and nutrition and by increasing the number of student enrollments and attendance rates. The program, whose goal is to break the intergenerational cycle of poverty by addressing nutrition, health and education in a comprehensive fashion, also has components designed to eradicate maternal mortality.

\section{The Right to Work}

(Recommendations in paragraph 93-Numbers 62 to 64)

48. The federal government has adopted measures to counteract the effects of the economic crisis and to combat poverty and marginalization. Among other measures, the National Agreement in Support of Family Fi- 
nances and Employment was signed on January 7, 2009, to protect jobs and workers, to create temporary job opportunities and to assist people who lose their jobs. In addition, on May 22, 2009, the National Agreement on Labor Productivity was signed to benefit more than 105,000 workers with training, which will enable small- and medium-sized businesses to have specialized technical assistance focused on productivity.

49. Periodically, the safety, health and dignified treatment of day workers and their families are monitored through inspection visits. From October to December, 2008, farmland was visited in 13 states to the benefit of 23,461 farm workers (17,248 men and 6,213 women). As a result, to date 2,433 technical safety and health standards have been indicated. From May to July and October to December of 2009, 150 farms will be visited and follow-up visits to the 2008 inspection tours will be made as well.

III. The Right to an Adequate Standard of Living, Especially Regarding Housing and Food

(Recommendations in paragraph 93- Numbers 70 to 72)

50. The Opportunities program assists more than five million families to improve their nutrition, health and education. In 2008, through the Rural Food Assistance and Supply Program, food aid was given to 129,603 families in marginalized rural locations and 22,553 stores in 20,402 highly marginalized and very highly marginalized rural areas were operated to provide basic and complementary goods at accessible prices. Under the Social Milk Support Program, subsidized, fortified milk is provided to $6,032,177$ people, of which 371,664 enrolled in the program in the first quarter of 2009.

51. As regards housing, the subsidized housing programs Tu Casa ("Your Home," administered by the National Fund for Low-Cost Housing) and Esta es tu Casa ("Make Yourself at Home," administered by the National Housing Commission), have benefited a total of 733,964 individuals with incomes of less than four minimum wages over the last two years $(298,093$ in 2007 and 435,871 in 2008). It is estimated that 291,865 individuals will benefit from the programs in 2009. In addition, under the Habitat Program, 8,324 construction and action programs have been undertaken in marginalized urban areas with a high concentration of poor households. 


\section{The Right to Education and Access to Culture}

\section{(Recommendations in paragraph 93- Numbers 73 and 74)}

52. The Mexican Constitution recognizes in article three that "all individuals have the right to an education" and that it should be secular and free. Article 38 of the General Law on Education states that "basic education at its three levels will be adapted as needed to respond to the linguistic and cultural characteristics of each one of the diverse indigenous groups in the country, as well as to the disperse rural population and migratory groups".

53. Primary and Secondary education is practically universal in coverage: for the $2008-2009$ school year, there is $97 \%$ coverage for primary education $(14,815,735$ children) and $95 \%$ coverage for secondary education $(6,153,459$ children). For indigenous education for the 2008-2009 school year, 383,006 children enrolled in pres-school $(50.3 \%$ boys and $49.7 \%$ girls), 841,151 in primary school (51.2 \% boys and $48.8 \%$ girls) and 19,355 in secondary school $(49.2 \%$ boys and $50.8 \%$ girls $)$. This represents an increase of $0.25 \%, 0.29 \%$ and $24 \%$ in pre-school, primary and secondary education, respectively, in comparison with the previous school year. Enrollment of migrant children totaled 2,761 in pre-school (50.9\% boys and $49.1 \%$ girls) and 2,710 children in primary school $(51.4 \%$ boys and $48.6 \%$ girls), representing an increase of $11.42 \%$ in pre-school and a decrease of $12.21 \%$ in primary school relative to the previous school year. In the border cities, it is usual for the children of migrants who cross the border to work in Mexico or who live in nearby cities of other countries to attend school. Several strategies have been combined to adapt the educational services to the needs of the indigenous and migrant children (educational materials in their languages; modular programs that can be completed gradually; educational services in the fields) and to provide health services and economic and food aid. There is a program to encourage the enrollment and retention of indigenous girls in rural schools. 54. On April 18, 2009, a reform to the General Act on Education entered into force that introduces as one of the guiding educational principles the fight against discrimination and violence, especially against women and children, and the obligation of educational institutions to create ways to measure their progress in applying methods to prevent and eliminate any form of discrimination and violence so that they can be evaluated in this area. It also requires education officials to 
facilitate the entrance, reentrance, continuance and departure of women, and to make parents or custodians aware of the importance of equal treatment for girls and of providing them with the same educational opportunities as boys. Mexico expects to receive the visit of the United Nations Special Rapporteur on the right to education in early 2010.

55. On April 30, 2009, the Constitution was amended to recognize in its article 4 that "all persons have the right to access culture and the enjoyment of the goods and services that the State provides in the matter, as well as the exercise of his/her cultural rights".

\section{The Right to Health}

\section{(Recommendations in paragraph 93- Numbers 68 to 70)}

56. In order to reduce maternal and neonatal mortality and to protect reproductive rights, in addition to the 2007-2012 Fair Start in Life Program (Programa Arranque Parejo en la Vida), on May 28, 2009, the National Strategy to Reduce Maternal Mortality was launched to provide universal care for complications pregnancies and to promote a culture of risk prevention and self-care for pregnant women. With this, the health and social security institutes will provide medical care free of charge to any woman whether or not she has social security if she suffers from any complication during the gestation period.

57. On January 5, 2009, a reform to the General Law on Health was published regarding palliative care. This introduces the right of terminally-ill individuals to receive comprehensive medical care including palliative care, and the related obligation of the institutions and their health personnel to provide this care in a comprehensive fashion to preserve the patients' quality of life through prevention, treatment and pain management and by addressing other physical and emotional symptoms in order to preserve their dignity.

\section{E. DISSEMINATION OF AND FOLLOW-UP}

TO THE RECOMMENDATIONS DERIVED FROM THE REVIEW

(Recommendations in paragraph 93-Numbers 82 and 83)

58. The government of Mexico has disseminated and will continue to disseminate widely the national report and the recommendations re- 
ceived from the Working Group on the Universal Periodic Review. Consistent with the commitment it has assumed, the Mexican government follows up on the recommendations of the Universal Periodic Review through a dialogue with civil society. It does this within the Subcommittee to Evaluate and Follow-up on the 2008-2012 National Human Rights Program, which is part of the Government's Human Rights Policy Commission, and established a working group that follows up the fulfillment of international commitments of the Mexican State in this framework. Agencies and entities of the federal government together with civil society organizations have begun to identify the objectives of the National Human Rights Program, as well as those of the current governmental programs, to promote the fulfillment of these recommendations. 